Gerontology 1983;29:361

\title{
Professor Gordon Lewis Mills
}

It is with great regret that this obituary has to be written. Gordon Mills played an important role in geriatric medicine in the United Kingdom. Before obtaining the Chair at Liverpool University, he was Consultant Geriatrician at the Central Middlesex Hospital and subsequently at St. Pancras Hospital, both in Greater London. Previously, he spent some time in general practice.

Besides taking an active interest in advances in experimental gerontology, he was particularly clinically interested in the diagnosis and treatment of accidental hypothermia and incontinence of urine. He was very much a clinical professor and played an active part in the management of patients under his care.

Amongst unpublished work he carried out was an investigation which strongly suggested that the inci-

dence in the use of bedstead safety sides (cot sides) for geriatric patients at night, was much more related to the attitude of the nurse rather than the condition of the patient - thus in wards under his control the use of safety sides was subsequently greatly reduced.

He has had a major part as a contributing editor to Gerontology since 1976, both in refereeing and making constructive suggestions for the improvement of many papers submitted to the Journal before publication. One of his own recent contributions to the literature was in 'Geriatrics for Everyday Practice' published by Karger, in which he was the senior author of a chapter entitled 'Diseases requiring physical rehabilitation'.

$\mathrm{H}$. He will be a great loss to his colleagues

his patients

his University

and his family.

J. Andrews

Isleworth 